\title{
A study on relationship between quality of work life and job satisfaction
}

\author{
Heydar Mohammadi ${ }^{a^{*}}$ and Mohsen Ameri Shahrabi ${ }^{b}$
}

${ }^{a}$ Senior Auditor, Supreme Audit Court, Tehran, Iran

${ }^{b}$ Faculty Member, Department of English and Management, Naragh Branch, Islamic Azad University, Naragh, Iran

\section{CH R O N I C L E}

Article history:

Received May 16, 2013

Received in revised format 18 August 2013

Accepted 18 August 2013

Available online

August 272013

Keywords:

Job satisfaction

Quality of work life

Team work \begin{abstract}
A B S T R A C T
A healthy and good work condition is often involved with other factors such as leadership style, management, etc. In this paper, we present an empirical investigation to study the effects of the quality of work life on job satisfaction. The study uses a standard questionnaire and distributes it among all 86 full time employees of two governmental agencies in Iran, Supreme Audit Court and Interior Ministry, and Cronbach alphas has been calculated as 0.92 . The main hypothesis of this survey considers the relationship between job satisfaction and quality of work life and there. There are also eleven sub-hypotheses associated with this survey including fair and sufficient payment, safe and healthy work conditions, equal job opportunities, rule of law, service training, integration and social cohesion, human development capabilities, organizational structure, delegation of authority, job satisfaction and employee participation. The results of survey have confirmed that there were some meaningful relationships between the quality of work life on job satisfaction in both organizations.
\end{abstract}

\section{Introduction}

These days, people spend most of their lives in their work environments and working conditions play essential role on how they feel about their job satisfaction (Bowditch \& Buono, 1982; Akdere, 2006). Therefore, it is essential to learn how management skills, healthy work conditions, etc. influence on job satisfaction. Hemmati et al. (2013), for instance, investigated the effects of the quality of work life on quality of family life. They used a standard questionnaire and distributed it among all 35 full time employees of a prison in province of Semnan, Iran. In their survey, quality of work life consisted of eight components including fair and sufficient payment, safe and healthy work conditions, human development capabilities, growth and secure opportunities, social integration, rule of law, general 
atmosphere of work life and social dependence of work life. They reported that having safe and healthy work conditions could strongly influence quality of family life.

Jiang (2012), in other survey, presented a model of work-life conflict and quality of employeeorganization relationships (EORs) based on transformational leadership, procedural justice, and family-supportive workplace initiatives. They examined EORs by introducing various kinds of worklife conflict as variables leading to EOR outcomes, and by looking into the possible effects of transformational leadership, procedural justice, and family-supportive workplace initiatives upon employees' perceptions of work-life conflict and relationships with their employers. They reported that time-based work-life conflict, individualized consideration, and procedural justice were positively associated with quality of EORs. They also reported that fair work-life policy-making procedures forecasted perceived levels of work-life conflict.

Keeney et al. (2013) attempted to move beyond work-family conflict to a broader conceptualization and measurement of work interference with life in two studies. In first study, evidence for the dimensionality of this measure was considered while in the second work interference with life indicated incremental validity above and beyond work interference with family with respect to job satisfaction, turnover intentions, life satisfaction, and mental health was investigated. The results of relative importance analyses were reported for the same outcomes.

Abbasi et al. (2012) compared quality of life and family performance among satisfied and unsatisfied groups of workers in industrial units of Ardabil province, Iran. They reported that there was a significant difference between satisfied and unsatisfied group regarding quality of life $\mathrm{P}<(0.05)$. However, there was no important difference between satisfied and unsatisfied group in terms of family performance.

Michel et al. (2009) executed a comprehensive meta-analysis of over 20 years of work-family conflict research. They applied an analysis on a series of path analyses to compare and contrast existing workfamily conflict models and presented a new model, which integrated and synthesized current workfamily theory and research. The results of their survey demonstrated that direct effects drive workfamily conflict models while indirect impacts could provide little incremental explanation in regards to satisfaction outcomes.

Trefalt et al. (2013) presented a model on the impact of rapid changes in national context on individuals' work-life conflict, satisfaction with work-life balance and work-life enrichment, based on the theoretical logics of three mechanisms including structural misalignment, social and temporal comparisons, and choice overload. They explained that to understand individuals' work-life experiences it is essential to consider national context as a dynamic rather than a static influence. They also provided a framework for systematic empirical examining of the impact of changes in national context on work-life experiences; and uncovered three mechanisms.

Greenhaus et al. (2003) studied the relationship between work-family balance and quality of life among professionals who worked for public accounting. They assessed three components of workfamily balance including time balance, involvement balance and satisfaction balance. For individuals who spent substantial amount of time in their combined work and family roles, those who invested more time on family than work experienced a higher quality of life than balanced individuals who, in turn, experienced a higher quality of life than those who took more time on work than family. They reported similar results for involvement and satisfaction and detected the contributions of the study to the work-family balance literature.

\section{The proposed study}

In this paper, we present an empirical investigation to study the effects of the quality of work life on job satisfaction. The study uses a standard questionnaire and distributes it among a sample of regular 
or managers from 86 full time employees of two governmental agencies in Iran, Supreme Audit Court and Interior Ministry. The sample size is calculated as follows,

$n=\frac{N \times z_{\alpha / 2}^{2} \times p \times q}{\varepsilon^{2} \times(N-1)+z_{\alpha / 2}^{2} \times p \times q}$,

where $N$ is the population size, $p=1-q$ represents the yes/no categories, $z_{\alpha / 2}$ is CDF of normal distribution and finally $\varepsilon$ is the error term. Since we have $p=0.5, z_{\alpha / 2}=1.96$ and $N=86$, the number of sample size is calculated as $n=78$. The proposed study distributes 36 questionnaires among employees of Interior ministry and 42 questionnaire among employees who worked for Supreme Audit Court. Cronbach alphas has been calculated as 0.92 , which validates the quality of the survey. Fig. 1 demonstrates educational backgrounds of the participants.

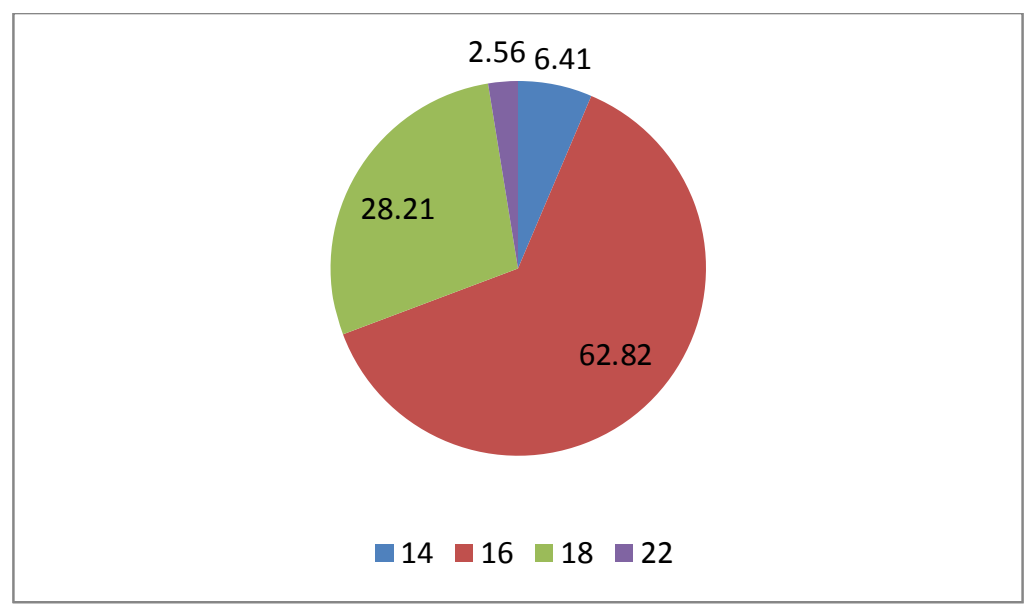

Fig. 1. Years of educational background

As we can observe from Fig. 1, most participants hold, at least, a bachelor of science degree, which means they are highly educated.

The main hypothesis of this survey considers the relationship between job satisfaction and quality of work life. Therefore, the main hypothesis of the survey is as follows,

Main hypothesis: There is a meaningful relationship between job satisfaction and quality of work life.

In addition, there are eleven hypotheses associated with the proposed study of this paper as follows,

1. Fair and sufficient payment influences job satisfaction, positively.

2. Safe and healthy work conditions influences job satisfaction, positively.

3. Equal job opportunities influences job satisfaction, positively.

4. Rule of law influences job satisfaction, positively.

5. Service training influences job satisfaction, positively.

6. Integration and social cohesion influences job satisfaction, positively.

7. Human development capabilities influence job satisfaction, positively.

8. Organizational structure influences job satisfaction, positively.

9. Delegation of authority influences job satisfaction, positively.

10. Job satisfaction influences job satisfaction, positively.

11. Employee participation influences job satisfaction, positively.

The proposed study of this paper designed a questionnaire in Likert scale and distributed among employees of two firms and using t-student we examine different hypotheses. 


\section{The results}

In this section, we present details of our finding on testing the main as well as eleven sub-hypotheses of the survey. Table 1 demonstrates the summary of our findings for Supreme Audit Court.

Table 1

The summary of testing various hypotheses for Supreme Audit Court

\begin{tabular}{|c|c|c|c|c|c|c|c|c|c|}
\hline \multirow{2}{*}{ Row } & & \multicolumn{5}{|c|}{ Capability } & \multirow{2}{*}{ Sum } & \multirow{2}{*}{\multicolumn{2}{|c|}{ Mean }} \\
\hline & & 1 & 2 & 3 & 4 & 5 & & & \\
\hline 1 & & 6 & 8 & 10 & 8 & 4 & 36 & 2.89 & \multirow{4}{*}{3.44} \\
\hline 2 & \multirow{3}{*}{ Competency } & 4 & & 8 & 20 & 4 & 36 & 3.56 & \\
\hline 3 & & & 8 & 4 & 20 & 4 & 36 & 3.56 & \\
\hline 4 & & 4 & & 8 & 12 & 12 & 36 & 3.78 & \\
\hline 5 & \multirow{3}{*}{ Formation } & & 20 & 8 & 4 & 4 & 36 & 2.78 & \multirow{3}{*}{2.78} \\
\hline 6 & & 4 & 8 & 16 & 4 & 4 & 36 & 2.89 & \\
\hline 7 & & 4 & 12 & 12 & 8 & & 36 & 2.67 & \\
\hline 8 & \multirow[t]{2}{*}{ Organizational structure } & 4 & 4 & 16 & 8 & 4 & 36 & 3.11 & \multirow{2}{*}{2.78} \\
\hline 9 & & 12 & 4 & 16 & & 4 & 36 & 2.44 & \\
\hline 10 & \multirow{3}{*}{ Performance measurement } & 12 & 4 & 12 & 8 & & 36 & 2.44 & \multirow{3}{*}{2.56} \\
\hline 11 & & 8 & 8 & 16 & & 4 & 36 & 2.56 & \\
\hline 12 & & 8 & 8 & 12 & 4 & 4 & 36 & 2.67 & \\
\hline 13 & \multirow{3}{*}{ Delegation } & 12 & 8 & 8 & 8 & & 36 & 2.33 & \multirow{3}{*}{2.33} \\
\hline 14 & & 12 & 8 & 8 & 8 & & 36 & 2.33 & \\
\hline 15 & & 16 & 4 & 8 & 4 & 4 & 36 & 2.33 & \\
\hline 16 & \multirow{4}{*}{ Reward system } & 12 & 4 & 8 & 12 & & 36 & 2.56 & \multirow{4}{*}{2.42} \\
\hline 17 & & 12 & 8 & 8 & 8 & & 36 & 2.33 & \\
\hline 18 & & 16 & 4 & 8 & 8 & & 36 & 2.22 & \\
\hline 19 & & 8 & 8 & 12 & 8 & & 36 & 2.56 & \\
\hline 20 & \multirow{3}{*}{ Being effective } & 4 & 4 & 4 & 24 & & 36 & 3.33 & \multirow{3}{*}{3.30} \\
\hline 21 & & 4 & 4 & 4 & 24 & & 36 & 3.33 & \\
\hline 22 & & 4 & 8 & & 24 & & 36 & 3.22 & \\
\hline 23 & \multirow{3}{*}{ Being meaningful } & 8 & & 8 & 24 & & 36 & 3.44 & \multirow{3}{*}{3.67} \\
\hline 24 & & & 4 & 4 & 20 & 8 & 36 & 3.89 & \\
\hline 25 & & & 4 & 8 & 20 & 4 & 36 & 3.67 & \\
\hline 26 & & & 8 & 12 & 16 & & 36 & 3.22 & \\
\hline 27 & Trust & 4 & & 8 & 24 & & 36 & 3.44 & 3.33 \\
\hline 28 & & & 8 & 8 & 20 & & 36 & 3.33 & \\
\hline 29 & & 4 & 4 & 4 & 24 & & 36 & 3.33 & \\
\hline 30 & Access to resources & 4 & 8 & 4 & 20 & & 36 & 3.11 & 3.15 \\
\hline 31 & & & 8 & 20 & 8 & & 36 & 3.00 & \\
\hline 32 & Being independent & 8 & 8 & 8 & 8 & 4 & 36 & 2.78 & 2.78 \\
\hline 33 & bemg maependent & 8 & 8 & 8 & 8 & 4 & 36 & 2.78 & 2.10 \\
\hline 34 & & & & 12 & 24 & & 36 & 3.67 & \\
\hline 35 & service training & & 8 & 4 & 20 & 4 & 36 & 3.56 & 311 \\
\hline 36 & service traming & 4 & 8 & 20 & 4 & & 36 & 2.67 & 5.11 \\
\hline 37 & & 8 & 8 & 16 & & 4 & 36 & 2.56 & \\
\hline 38 & & 12 & 8 & 4 & 12 & & 36 & 2.44 & \\
\hline 39 & & 8 & 12 & 12 & 4 & & 36 & 2.33 & \\
\hline 40 & & 12 & 4 & 12 & 4 & 4 & 36 & 2.56 & \\
\hline 41 & & 8 & 8 & 12 & 4 & 4 & 36 & 2.67 & \\
\hline 42 & Participatory management & 8 & 8 & 12 & 4 & 4 & 36 & 2.67 & 2.88 \\
\hline 43 & & 12 & 12 & 8 & & 4 & 36 & 2.22 & \\
\hline 44 & & 4 & 12 & 8 & & 12 & 36 & 3.11 & \\
\hline 45 & & & & & 12 & 24 & 36 & 4.67 & \\
\hline 46 & & 4 & 4 & 8 & 20 & & 36 & 3.22 & \\
\hline
\end{tabular}


In addition, Table 2 demonstrates the summary of our findings for ministry of interior.

Table 2

The summary of testing various hypotheses for ministry of interior

\begin{tabular}{|c|c|c|c|c|c|c|c|c|c|}
\hline \multirow{2}{*}{ Row } & & \multicolumn{5}{|c|}{ Capabilities } & \multirow{2}{*}{$\begin{array}{c}\text { Total } \\
\text { Responses } \\
\end{array}$} & \multirow{2}{*}{\multicolumn{2}{|c|}{ Mean }} \\
\hline & & 1 & 2 & 3 & 4 & 5 & & & \\
\hline 1 & \multirow{4}{*}{ Competency } & 16 & 8 & 10 & & 8 & 42 & 2.43 & \multirow{4}{*}{2.80} \\
\hline 2 & & 8 & 6 & 12 & 14 & 2 & 42 & 2.90 & \\
\hline 3 & & 8 & 10 & 2 & 12 & 10 & 42 & 3.14 & \\
\hline 4 & & 8 & 14 & 6 & 10 & 4 & 42 & 2.71 & \\
\hline 5 & \multirow{3}{*}{ Formation } & 6 & 12 & 6 & 14 & 4 & 42 & 2.95 & \multirow{3}{*}{3.71} \\
\hline 6 & & 6 & 14 & 14 & 8 & 20 & 42 & 4.95 & \\
\hline 7 & & 4 & 12 & 6 & 10 & 10 & 42 & 3.24 & \\
\hline 8 & \multirow[t]{2}{*}{ Organizational structure } & 4 & 18 & 8 & 6 & 6 & 42 & 2.81 & \multirow{2}{*}{2.79} \\
\hline 9 & & & 16 & 20 & 6 & & 42 & 2.76 & \\
\hline 10 & \multirow{3}{*}{ Performance measurement } & & 12 & 12 & 10 & 8 & 42 & 3.33 & \multirow{3}{*}{3.35} \\
\hline 11 & & & 8 & 18 & 10 & 6 & 42 & 3.33 & \\
\hline 12 & & & 12 & 10 & 12 & 8 & 42 & 3.38 & \\
\hline 13 & \multirow{3}{*}{ Delegation } & & 16 & 16 & 8 & 2 & 42 & 2.90 & \multirow{3}{*}{2.76} \\
\hline 14 & & & 14 & 20 & 6 & 2 & 42 & 2.90 & \\
\hline 15 & & 12 & 10 & 10 & 8 & 2 & 42 & 2.48 & \\
\hline 16 & \multirow{4}{*}{ Reward system } & 6 & 10 & 12 & 10 & 4 & 42 & 2.90 & \multirow{4}{*}{3.00} \\
\hline 17 & & 8 & 4 & 12 & 16 & 2 & 42 & 3.00 & \\
\hline 18 & & & 12 & 18 & 10 & 2 & 42 & 3.05 & \\
\hline 19 & & & 12 & 16 & 14 & & 42 & 3.05 & \\
\hline 20 & \multirow{3}{*}{ Being effective } & 14 & 2 & 12 & 12 & 2 & 42 & 2.67 & \multirow{3}{*}{2.67} \\
\hline 21 & & 10 & 12 & 12 & 2 & 6 & 42 & 2.57 & \\
\hline 22 & & 10 & 10 & 10 & 4 & 8 & 21 & 2.76 & \\
\hline 23 & \multirow{3}{*}{ Being meaningful } & 10 & 12 & 8 & 8 & 4 & 42 & 2.62 & \multirow{3}{*}{2.62} \\
\hline 24 & & 8 & 16 & 12 & 4 & 2 & 42 & 2.43 & \\
\hline 25 & & & 22 & 8 & 10 & 2 & 42 & 2.81 & \\
\hline 26 & & & 16 & 18 & 6 & & 42 & 2.62 & \\
\hline 27 & Trust & & 16 & 14 & 8 & 4 & 42 & 3.00 & 2.78 \\
\hline 28 & & 4 & 12 & 16 & 2 & 6 & 42 & 2.71 & \\
\hline 29 & & & 10 & 18 & 10 & 4 & 42 & 3.19 & \\
\hline 30 & Access to resources & & 16 & 20 & 6 & & 42 & 2.76 & 2.90 \\
\hline 31 & & & 18 & 16 & 8 & & 42 & 2.76 & \\
\hline 32 & & 6 & 4 & 18 & 8 & 6 & 42 & 3.10 & \\
\hline 33 & Being independent & 6 & 16 & 10 & 6 & 4 & 42 & 2.67 & 2.88 \\
\hline 34 & & 2 & 6 & 20 & 12 & 2 & 42 & 3.14 & \\
\hline 35 & Service training & 4 & 10 & 12 & 8 & 8 & 42 & 3.14 & 330 \\
\hline 36 & Service training & 4 & 18 & 12 & 2 & 6 & 42 & 2.71 & 3.30 \\
\hline 37 & & & 2 & 6 & 16 & 18 & 42 & 4.19 & \\
\hline 38 & & & 8 & 4 & 18 & 12 & 42 & 3.81 & \\
\hline 39 & & & 8 & 4 & 16 & 14 & 42 & 3.86 & \\
\hline 40 & & 4 & 12 & 6 & 10 & 10 & 42 & 3.24 & \\
\hline 41 & & 4 & 12 & 10 & 12 & 4 & 42 & 3.00 & \\
\hline 42 & Participatory management & 6 & 2 & 14 & 10 & 10 & 42 & 3.38 & 3.20 \\
\hline 43 & & 10 & 4 & 18 & 2 & 6 & 42 & 2.62 & \\
\hline 44 & & 4 & 10 & 8 & 16 & 4 & 42 & 3.14 & \\
\hline 45 & & 6 & 8 & 10 & 8 & 10 & 42 & 3.19 & \\
\hline 46 & & 16 & 8 & 4 & 8 & 6 & 42 & 2.52 & \\
\hline
\end{tabular}


The results of Table 1 and Table 2 clearly confirm all 11 hypotheses of the survey in both organizations. The mean of responses for Supreme Audit Course and Ministry of Interior are 2.964 and 2.982 , respectively.

\section{Conclusion}

In this paper, we have presented an empirical investigation to study the effects of the quality of work life on job satisfaction in two Iranian organizations. The proposed study designed a questionnaire in Likert scale and distributed it among some employees of the organizations and using some basic statistics examined the main and eleven sub-hypotheses of the survey. The results of our survey have indicated that different working components have significantly influenced on job satisfaction. While many believe that raising wages is the only way to increase people's job satisfaction, the results of this survey indicated that there are other low cost actions, which could increase employees' job satisfaction. For instance, participatory management is among important actions, which has no financial burden but it could increase employees' motivation to become more interested in their jobs.

Trust is another important factor in increasing job satisfaction and it was more important in Supreme Audit Court than the other organization. Training services, in our survey, was another important component. This item does not have significant amount of financial burden on any of these two firms but the outcome of having such courses is believed to be significant. Finally, the moral story is that having a better society is a primary objective of any society in the world and it is important to reach this goal by creating a better work conditions.

\section{References}

Abbasi, M., Samadzadeh, M., \& Shahbazzadegan, B. (2011). Comparison of quality of life and family performance in satisfied and unsatisfied groups of staffs in industrial units of Ardabil province. Procedia-Social and Behavioral Sciences, 15, 1936-1941.

Akdere, M. (2006). Improving quality of work-life: Implications for human resources. The Business Review, 6(1), 173-177.

Bowditch, J. L., \& Buono, A. F. (1982). Quality of Work Life Assessment: A Survey-Based Approach. Boston, MA: Auburn House Publishing Company.

Greenhaus, J. H., Collins, K. M., \& Shaw, J. D. (2003). The relation between work-family balance and quality of life. Journal of Vocational Behavior, 63(3), 510-531.

Hemmati, A., Hemmati, M., \& Kia, S.H. (2013). Investigating the effect of quality of work life on quality of family life. Management Science Letters, 3(9), 2411-2416.

Jiang, H. (2012). A model of work-life conflict and quality of employee-organization relationships (EORs): Transformational leadership, procedural justice, and family-supportive workplace initiatives. Public Relations Review,38(2), 231-245.

Keeney, J., Boyd, E. M., Sinha, R., Westring, A. J., \& Ryan, A. M. (2013). From "Work-family" to "Work-life": Broadening Our Conceptualization and Measurement. Journal of Vocational Behavior, 82(3), 221-237.

Michel, J. S., Mitchelson, J. K., Kotrba, L. M., LeBreton, J. M., \& Baltes, B. B. (2009). A comparative test of work-family conflict models and critical examination of work-family linkages. Journal of Vocational Behavior, 74(2), 199-218.

Trefalt, Š., Drnovšek, M., Svetina-Nabergoj, A., \& Adlešič, R. V. (2013). Work-life experiences in rapidly changing national contexts: Structural misalignment, comparisons and choice overload as explanatory mechanisms. European Management Journal, 31(5), 448-463. 